\title{
Synthesis of Novel Pyrazole Derivatives as Promising DNA-Binding Agents and Evaluation of Antitumor and Antitopoisomerases I/II Activities
}

\author{
Jiajia Feng, ${ }^{a}$ Hui Qi, ${ }^{a}$ Xiaoyang Sun,${ }^{a}$ Siran Feng,${ }^{a}$ Zhenming Liu, ${ }^{b}$ Yali Song, ${ }^{*, a}$ and \\ Xiaoqiang Qiao*,a,c \\ ${ }^{a}$ Key Laboratory of Pharmaceutical Quality Control of Hebei Province, College of Pharmaceutical Sciences, Hebei \\ University; Baoding 071002, China: ${ }^{b}$ Drug Design Center, State Key Laboratory of Natural and Biomimetic Drugs, \\ School of Pharmaceutical Sciences, Peking University; Beijing 100191, China: and ${ }^{c}$ Key Laboratory of Medicinal \\ Chemistry and Molecular Diagnosis of Ministry of Education, Hebei University; Baoding 071002, China. \\ Received July 18, 2018; accepted August 19, 2018; advance publication released online September 7, 2018
}

\begin{abstract}
Molecules bearing pyrazole nucleus present diverse biological properties such as antitumor and antiinflammatory activities that can be associated with DNA interactions. This study aimed to the synthesis of new pyrazol derivatives and evaluated their ability to interact with the DNA and antitumor and topoisomerase inhibition activities. All derivatives were successfully synthesized, and their structures were elucidated by ${ }^{1} \mathrm{H}-\mathrm{NMR}$ and high resolution (HR)-MS (electrospray ionization positive mode $\left(\mathrm{ESI}^{+}\right)$). Antiproliferative inhibition assays, UV titration assays, fluorescence titration assays, circular dichroism (CD) assays, KI quenching studies, topoisomerase inhibitory activity assays and molecular docking were evaluated for these compounds. Especially, compounds $5 \mathrm{e}$ and $5 \mathrm{q}$ showed higher antitumor activity with $\mathrm{IC}_{50}$ values $<13 \mu \mathrm{M}$ for the tested cell lines. However, compounds $5 \mathrm{e}$ and $5 \mathrm{q}$ did not inhibit the topoisomerase activity evaluated by relaxation assay. These results show that the pyrazole nucleus contributes to the incorporation of molecules into the DNA. Moreover, it was highlighted that positive charges are relevant for the design of promising antitumor and DNA binding compounds.
\end{abstract}

Key words pyrazole; DNA; antitumor; antitopoisomerase

Cancer has always been a dreadful disease and continues to attract extensive research investigations. An estimated 8.2 million deaths are reported in 2012 worldwide, the annual number of new cases due to cancer is projected to rise from 14.1 million in 2012 to 21.6 million by 2030 with an increase in the death rate by $60 \%{ }^{1)}$ Various targets have been identified to restrain cancer among these DNA happens to be the most explored one. DNA is an important biological material whose base sequence controls the heredity of life and is the primary target for most anticancer and antiviral therapies. ${ }^{2)}$ The DNA binders are classified into three categories based on their mode of interaction, such as I) intercalators II) groove binders III) and combilexins. ${ }^{3)}$

Topoisomerase is a vital nuclear enzyme involved in various DNA processes and also important targets for inhibiting the cell proliferation. These are nuclear enzymes that transiently break one or two strands of DNA allowing to solve various DNA topological problems associated with DNA replication, transcription, recombination, and other vital cellular processes. ${ }^{4,5)}$ DNA topoisomerases are generally classified into topoisomerase I (topo I) and topoisomerase II (topo II) depending on their mechanism of action, making either singleor double-stranded breaks, respectively. ${ }^{6)}$

To date, some topoisomerase inhibitors, such as camptothe$\operatorname{cin}(\mathrm{CPT})^{7)}$ and its derivatives that target topo I and etoposide $(\mathrm{VP}-16){ }^{8)}$ doxorubicin $^{9)}$ and mitoxantrone ${ }^{10)}$ which target topo II, have been clinically used as potent anticancer drugs.

Pyrazole has shown a variety of biological and pharmacological properties. As potential antitumor compounds, they have shown good antitumor activity, multiple targets and high selectivity in vitro. ${ }^{11,12)}$ Lansiaux et al. studied a correlation between DNA binding affinity and nuclear uptake, and have found cationic drugs can be delivered selectively to the cell nucleus. It has been postulated that they gain entry into the cell via the human organic cation transporter 1 (hOCT1). ${ }^{13)}$ Based on this information, our research group had synthesized new 1,3,5-triphenyl pyrazole derivatives which different cationic groups were used as side chains. Therefore, these compounds may easily cross the cell membrane and accumulate in the nucleus and enhance anticancer activity. These compounds were evaluated for their DNA interaction ability, giving the binding mode and affinity with DNA molecule. In addition, it was also analyzed the antiproliferative activity on tumor cells and inhibition of the topoisomerase enzyme.

\section{Results and Discussion}

Chemistry The synthetic strategy for the preparation of 1,3,5-triphenyl pyrazole is outlined in the Chart 1. Using Claisene-Schmidt condensation reaction ${ }^{14-17)}$ compound $\mathbf{1}$ were synthesized. Reactions were base catalyzed, without any protection of hydroxyl groups. In the first step, $20 \% \mathrm{NaOH}$ aqueous solution was added to the solution of equimolar amounts of aryl ketone and aryl aldehyde in ethanol to obtain compound 1. Next, compound $\mathbf{2}$ was prepared by oxidation of compound 1. In the next step, compound $\mathbf{3}$ was synthesized in quantitative yield by the treatment of phenylhydrazine and compound $\mathbf{2}$ in ethanol. Compound $\mathbf{4}$ was synthesized by compound $\mathbf{3}$ and dibromo alkane in the presence of pure water, $\mathrm{KOH}$ and tetrabutylammonium bromide (TBAB). Finally, compound $\mathbf{4}$ and aliphatic amine were reacted in the pres- 


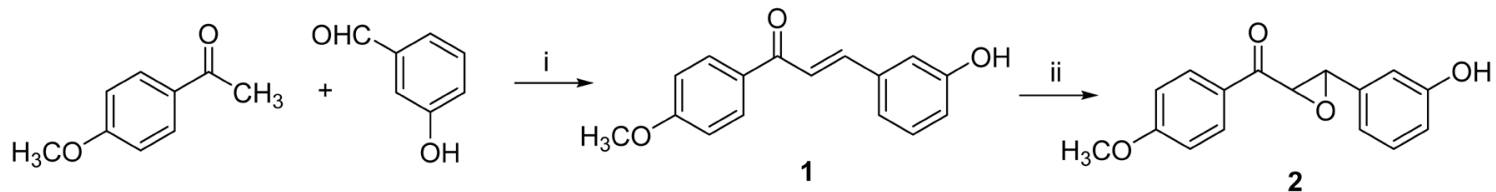<smiles>CC#CC(C)(C)C(=O)Oc1cccc(-c2cc(-c3cccc(OC)c3)n(-c3ccccc3)n2)c1</smiles>

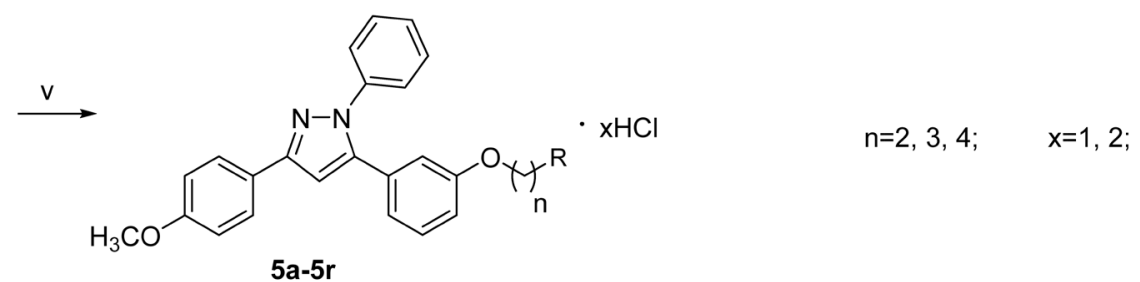

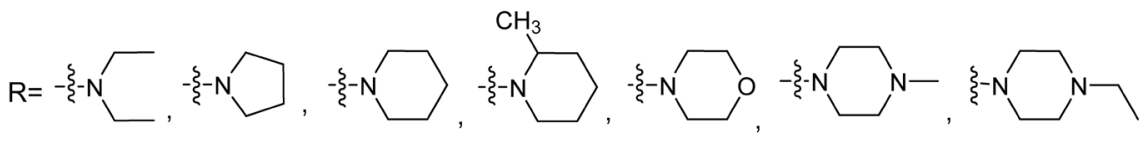

ence of $\mathrm{KI}, \mathrm{K}_{2} \mathrm{CO}_{3}$ and acetonitrile reflux for $7 \mathrm{~h}$ to give the crude product. The crude product was dissolved in acetone, and then $\mathrm{HCl}$ was added into the solution to adjust the $\mathrm{pH}$ to $2-3$, and white precipitates precipitated, then filtered to get the final product $(\mathbf{5} \mathbf{a}-\mathbf{5 r})$ (see Table 1). All the compounds were confirmed by ${ }^{1} \mathrm{H}-\mathrm{NMR}$ and high resolution (HR)-MS (electrospray ionization positive mode $\left(\mathrm{ESI}^{+}\right)$).

\section{Biological Activity}

Antiproliferative Activity The antitumor potency of target compounds against four human cancer cell lines including MCF-7 (breast cancer), MGC-803 (gastric cancer), HeLa (cervical cancer), and Huh-7 (liver cancer) cells were evaluated by 3-(4,5-dimethylthiazol-2-yl)-2,5-diphenyltetrazolium bromide (MTT) assay. Camptothecin and etoposide were used as positive controls. The results were shown in Table 2. By comparing the $\mathrm{IC}_{50}$ values, compounds $\mathbf{5 e}$ and $\mathbf{5 q}$ showed higher antitumor activity with $\mathrm{IC}_{50}$ values $<13 \mu \mathrm{M}$ for all tested cell lines. Compound $\mathbf{5 f}$ showed good inhibitory activity selectivity for MGC-803 as well as Huh-7, and compound 5k selectivity for Huh-7. Furthermore, compound 5d had relatively weak inhibitory activity in the four cancer cell lines. The preliminary results are promising, and some of these compounds may be potential candidates for new anticancer agents.

\section{DNA Binding Studies}

To find out the nature of the interaction of active congeners 5e and 5q with DNA, biophysical studies such as UV-visible spectroscopy, fluorescence spectroscopy and circular dichro- ism spectroscopy were carried out.

UV-Visible Absorption Spectroscopy To examine the binding nature of active congeners $\mathbf{5 e}$ and $\mathbf{5 q}$ to DNA, the UV absorption spectra of these congeners in the presence and absence of increasing concentrations of circulating tumor DNA (ctDNA) were examined. UV-visible studies are useful in understanding the mode of binding of these compounds with DNA. In general, hypochromism combined with a red shift is considered as an indication of intercalation of small molecules into DNA due to the stacking of the chromophore pairs. The hyperchromism originates from the breaking of the DNA secondary structure with contraction in the axis of the helix; while hypochromism results from the stabilization of the double stranded DNA either by intercalation or electrostatic effect and groove binding. ${ }^{18)}$ The maxima absorption wavelength of $\mathbf{5 e}$ and $\mathbf{5 q}$ in the absence of ctDNA was 207 and $208 \mathrm{~nm}$, respectively. Absorption spectra of $\mathbf{5 e}$ and $\mathbf{5 q}$ showed that as the concentration of ctDNA increases, the curve presents hypochromism without any red or blue shift. Hypochromic effect without any red or blue shift can be suggested that the groove binding is the most susceptible mode of $\mathbf{5 e}$ and $\mathbf{5 q}$ with ctDNA. ${ }^{19)}$ (Fig. 1). $K_{\mathrm{b}}$ of the compounds were determined using the following Formula:

$$
[\mathrm{DNA}] /\left(\varepsilon_{\mathrm{A}}-\varepsilon_{\mathrm{F}}\right)=[\mathrm{DNA}] /\left(\varepsilon_{\mathrm{B}}-\varepsilon_{\mathrm{F}}\right)+1 / K_{\mathrm{b}}\left(\varepsilon_{\mathrm{B}}-\varepsilon_{\mathrm{F}}\right)
$$

where [DNA] is the concentration of ctDNA. In the formula, $\varepsilon_{\mathrm{A}}=$ the apparent absorption coefficient, $\varepsilon_{\mathrm{F}}=$ the extinction coefficient of the free compound, $\varepsilon_{\mathrm{B}}=$ the extinction coefficient of the compound when fully bound to DNA, respectively. In 
Table 1. Structure of Compounds $\mathbf{5 a}-\mathbf{5 r}$

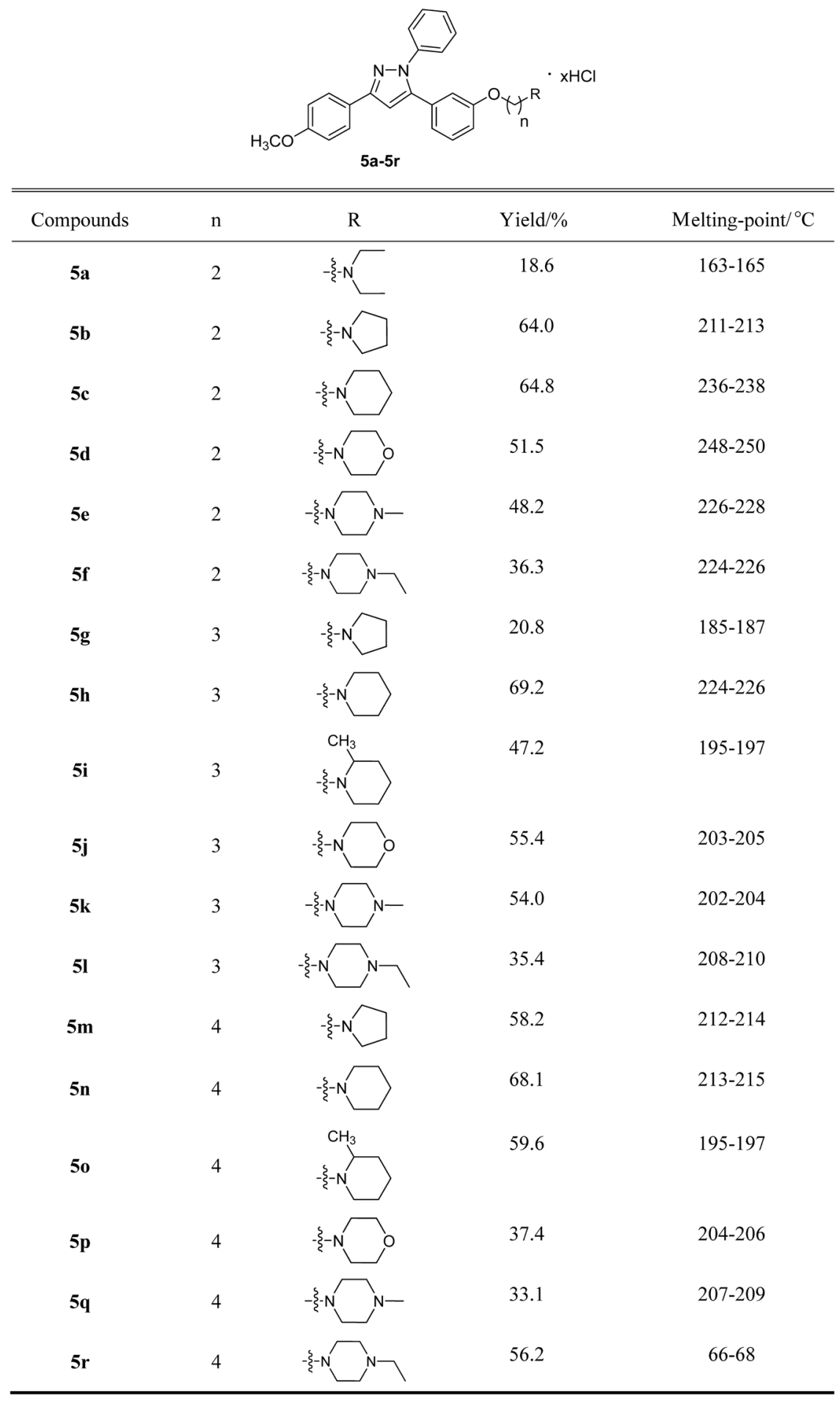

plots of [DNA] $/\left(\varepsilon_{\mathrm{A}}-\varepsilon_{\mathrm{F}}\right)$ versus [DNA], $K_{\mathrm{b}}$ is given by the ratio of the slope to the intercept (Table 3).

Fluorescence Titrations To further evaluate the ctDNA interaction, the corresponding binding parameters were also determined by fluorescence spectroscopy. This fluorescence titrations assay can provide information on the nature and affinity of binding on ctDNA. ${ }^{20)}$ On addition of equal increments of ctDNA solution to the solution of $\mathbf{5 e}$ and $\mathbf{5 q}$, the hypochromicity of fluorescence emission intensity at $396 \mathrm{~nm}$ was observed, which probably indicates a non-intercalative mode of binding such as electrostatic binding mode (surface binding or groove binding) that leads to effective protection of $\mathbf{5 e}$ and $\mathbf{5 q}$ molecules by ctDNA. However, the less intense fluorescence peaks intensity of 5e at $480-510 \mathrm{~nm}$ exhibited gradual enhancement with the addition of ctDNA. The enhancement in the fluorescence peaks at high wavelength may be due to a partial intercalating portion of $\mathbf{5 e}$ with ctDNA. The fluorescence spectra of $\mathbf{5 e}$ and $\mathbf{5 r}$ were shown in Fig. 2.

Circular Dichroism (CD) Studies CD has been found to be a reliable technique for detecting DNA minor groove 
Table 2. The $\mathrm{IC}_{50}$ Values of Compounds $\mathbf{5 a}-\mathbf{5 r}$ against Various Human Cancer Cells

\begin{tabular}{|c|c|c|c|c|}
\hline \multirow{2}{*}{ Compounds } & \multicolumn{4}{|c|}{$\mathrm{IC}_{50}(\mu \mathrm{M})$} \\
\hline & MCF-7 & MGC-803 & HeLa & Huh-7 \\
\hline Camptothecin & $2.86 \pm 1.25$ & $4.35 \pm 0.47$ & $3.26 \pm 0.30$ & $1.28 \pm 0.50$ \\
\hline Etoposide & $1.56 \pm 0.75$ & $2.61 \pm 0.74$ & $3.02 \pm 0.80$ & $1.35 \pm 0.66$ \\
\hline $5 \mathbf{a}$ & $>60$ & $26.48 \pm 1.13$ & $30.11 \pm 3.60$ & $49.18 \pm 1.13$ \\
\hline $5 b$ & $30.96 \pm 1.76$ & $46.14 \pm 1.32$ & $34.05 \pm 1.65$ & $31.85 \pm 1.32$ \\
\hline $5 c$ & $52.65 \pm 5.72$ & $>60$ & $38.37 \pm 0.95$ & $>60$ \\
\hline $5 d$ & $>60$ & $>60$ & $>60$ & $>60$ \\
\hline $5 e$ & $12.62 \pm 2.53$ & $8.72 \pm 2.17$ & $12.16 \pm 2.81$ & $5.46 \pm 2.83$ \\
\hline $5 f$ & $18.97 \pm 2.00$ & $11.66 \pm 3.46$ & $17.32 \pm 1.81$ & $7.67 \pm 2.11$ \\
\hline $5 g$ & $48.35 \pm 1.68$ & $>60$ & $32.27 \pm 1.80$ & $>60$ \\
\hline $5 \mathrm{~h}$ & $47.89 \pm 1.70$ & $>60$ & $>60$ & $>60$ \\
\hline $5 i$ & $>60$ & $29.56 \pm 4.36$ & $>60$ & $39.93 \pm 2.94$ \\
\hline $5 \mathbf{j}$ & $>60$ & $30.80 \pm 1.78$ & $>60$ & $46.80 \pm 5.63$ \\
\hline $5 \mathbf{k}$ & $43.92 \pm 1.67$ & $16.39 \pm 2.40$ & $21.65 \pm 1.50$ & $9.12 \pm 2.47$ \\
\hline 51 & $>60$ & $46.01 \pm 2.33$ & $57.62 \pm 1.33$ & $>60$ \\
\hline $5 \mathrm{~m}$ & $>60$ & $50.24 \pm 1.53$ & $50.03 \pm 5.60$ & $21.67 \pm 3.23$ \\
\hline $5 n$ & $>60$ & $28.37 \pm 1.98$ & $51.01 \pm 1.17$ & $54.52 \pm 3.46$ \\
\hline 50 & $58.35 \pm 1.72$ & $17.50 \pm 1.22$ & $>60$ & $48.13 \pm 6.20$ \\
\hline $5 p$ & $>60$ & $36.01 \pm 0.87$ & $53.25 \pm 1.50$ & $57.72 \pm 1.51$ \\
\hline $5 q$ & $12.97 \pm 1.36$ & $6.86 \pm 0.84$ & $9.28 \pm 2.76$ & $9.12 \pm 2.47$ \\
\hline $5 r$ & $>60$ & $23.46 \pm 2.00$ & $20.01 \pm 2.69$ & $>60$ \\
\hline
\end{tabular}

Each value represents the Mean \pm standard deviation (S.D.) from three different experiments, performed in triplicate. Camptothecin and etoposide were used as positive controls.

A) 5 e $(0.15 \mu \mathrm{M})$

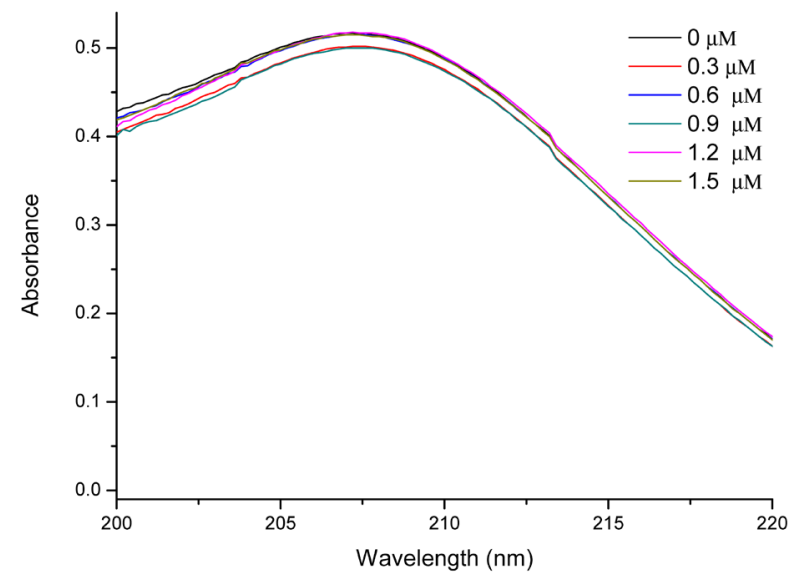

B) $5 \mathbf{q}(0.15 \mu \mathrm{M})$

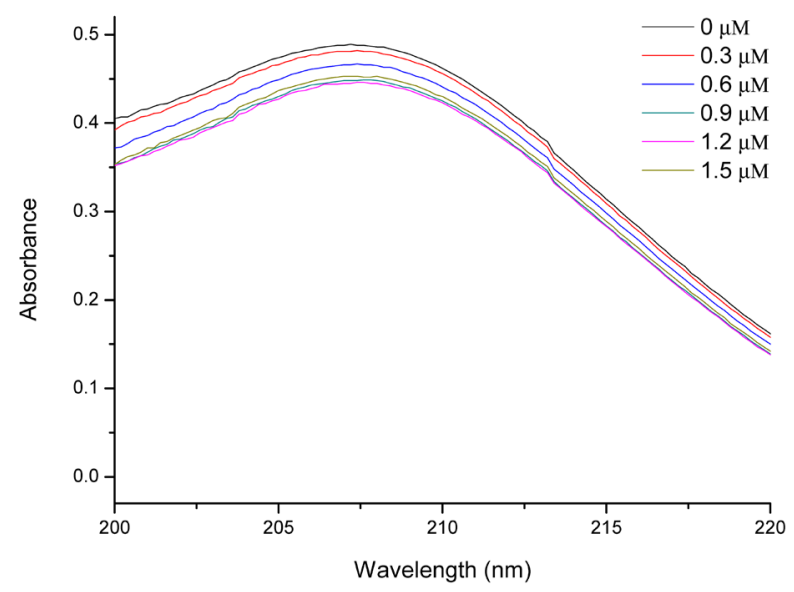

Fig. 1. Absorbance Changes after Interaction of A) 5e $(0.15 \mu \mathrm{M})$ and B) $\mathbf{5 q}(0.15 \mu \mathrm{M})$ with ctDNA.

$([\mathrm{ctDNA}]=0,0.3,0.6,0.9,1.2,1.5 \mu \mathrm{M})$. (Color figure can be accessed in the online version.)
Table 3. DNA Binding Data for Compounds

\begin{tabular}{ccccc}
\hline \hline Compound & $\begin{array}{c}\lambda \\
(\mathrm{nm})\end{array}$ & $\begin{array}{c}\text { Change in } \\
\text { abs. }\end{array}$ & $\begin{array}{c}\text { Bathochromism } \\
(\mathrm{nm})\end{array}$ & $K_{\mathrm{b}}\left(\mathrm{M}^{-1}\right)$ \\
\hline $\mathbf{5 e}$ & 207 & Hypochromism & 0 & $1.98( \pm 0.04) \times 10^{4}$ \\
$\mathbf{5 q}$ & 208 & Hypochromism & 0 & $3.88( \pm 0.06) \times 10^{4}$ \\
\hline
\end{tabular}

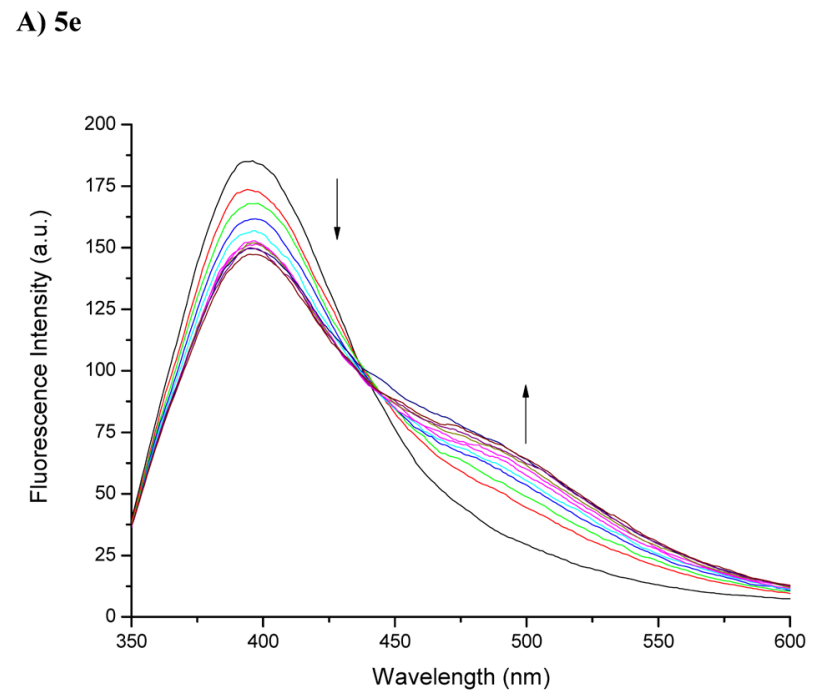

B) 5 q

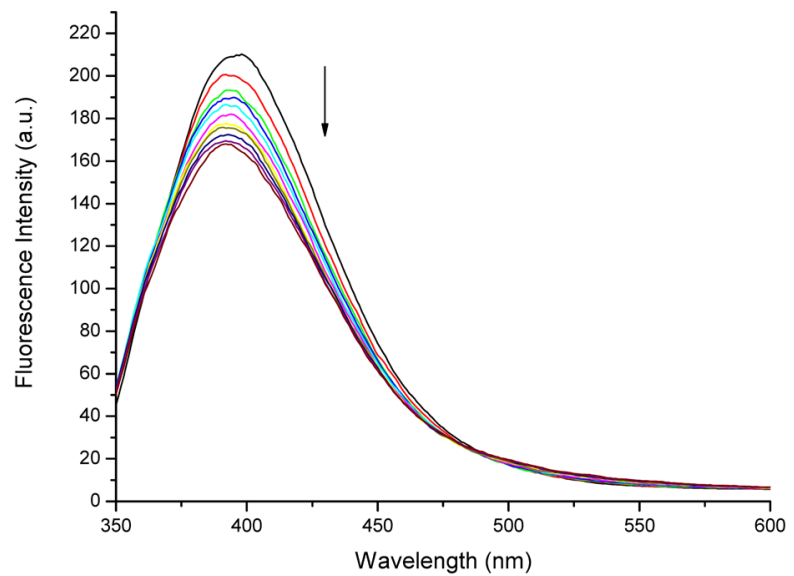

Fig. 2. Fluorescence Spectra Depicts the Interaction of Compounds A) 5e $(10 \mu \mathrm{M})$ and B) 5q $(10 \mu \mathrm{M})$ with Increasing Concentrations of ctDNA at $25^{\circ} \mathrm{C}$

$([\mathrm{ctDNA}]=0,10,20,30,40,50,60,70,80,90,100 \mu \mathrm{M})$. (Color figure can be accessed in the online version.)

binding by small molecules. CD monitors the interaction of a compound to the double helix; thus, a large induced CD signal implies minor groove binding because in this interaction, ligands would be in proximity to the chiral sugars. Conversely, intercalators induce little or no induced CD signal, as they bind far from the chiral sugars. ${ }^{21}$ We observed CD spectra of several of the new compounds to determine if they are binding in the DNA minor groove. Figure 3 showed that the $\mathrm{CD}$ spectra for the interaction between ctDNA and two of the compounds (5e and $\mathbf{5 q})$. All of the two compounds showed very strong induced $\mathrm{CD}$ signals which demonstrate the ctDNA minor groove binding of these compounds (Fig. 3). 
KI Quenching Studies Iodide quenching experiments were conducted on the same fluorescence spectrophotometer described previously. Iodide ions can effectively quench the fluorescence intensity of the small molecule in an aqueous medium. ${ }^{22,23)}$ In the presence of DNA, iodide ions are repelled by similarly charged phosphate backbone of DNA and any small molecule that penetrates inside DNA helix is well protected from being quenched by these negatively charged quenchers. However, electrostatically bounded molecules, as well as
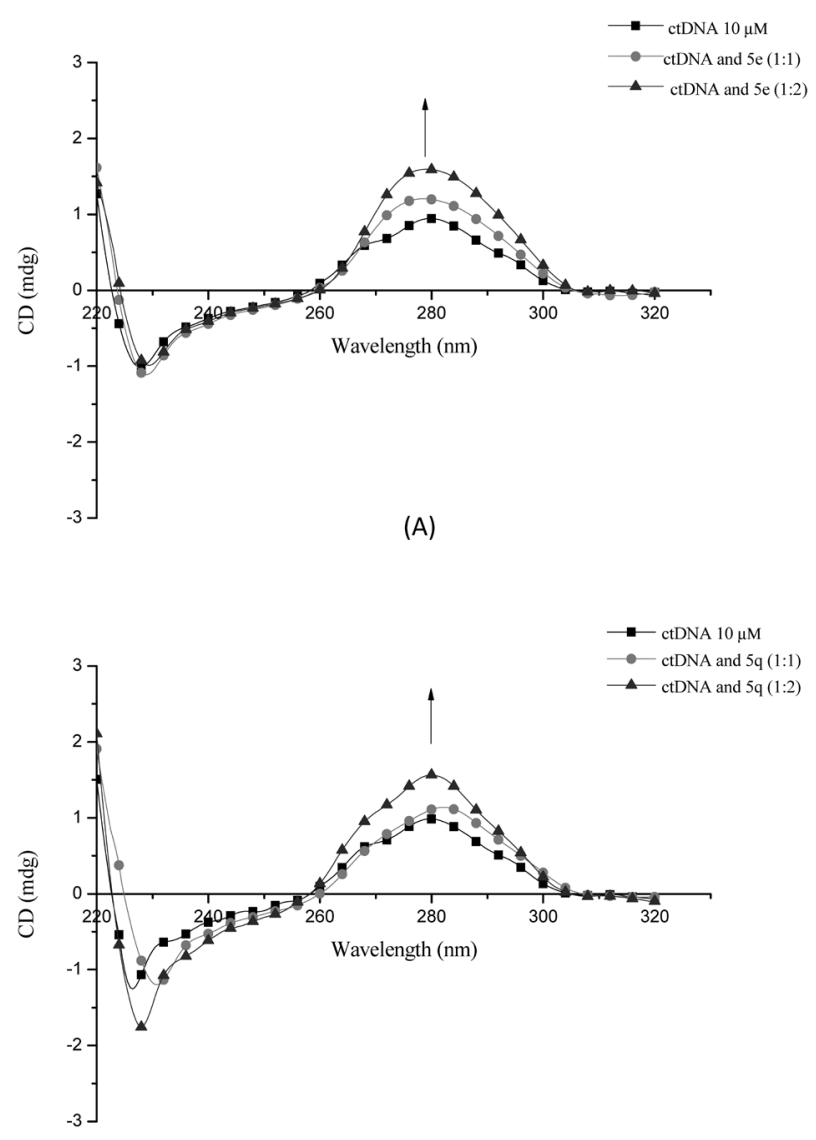

(B)

Fig. 3. Circular Dichroism Spectroscopy of (A) 5e and (B) 5q with ctDNA

A) 5 e

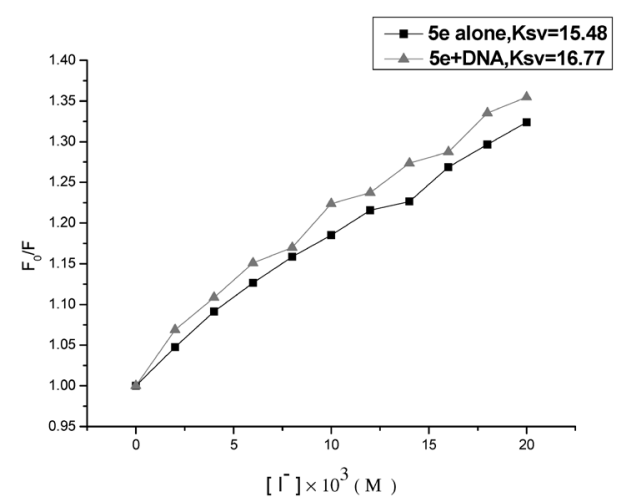

groove binders, are not well protected from anionic quenchers even in the presence of DNA environment and are readily quenched by $\mathrm{KI}^{24)}$ The quenching was investigated by gradually adding KI to compound and compound-ctDNA complex solutions to measure the relative accessibilities of the free and bound compound. Varying concentrations of KI $(0-20 \mathrm{~mm})$ were added to the compound $(10 \mu \mathrm{M})$ and compound-ctDNA (containing $10 \mu \mathrm{M}$ compound and $40 \mu \mathrm{M}$ ctDNA) solutions, respectively. The quenching constants in the absence and presence of ctDNA were calculated and then compared to analyze the interaction mode of the compound with ctDNA.

Figure 4 revealed the quenching behaviors of $\mathrm{KI}$ in the compound and compound-ctDNA systems. It was seen that the $K \mathrm{sv}$ values of 5e were 15.48 and $16.77 \mathrm{~L} \mathrm{~mol}^{-1}$, and that the $K$ sv values of $\mathbf{5 q}$ were 20.57 and $24.82 \mathrm{~L} \mathrm{~mol}^{-1}$ without and with ctDNA, which indicated that the double helix of ctDNA could not protect the compound from the anionic quencher. Therefore, the interaction mode of the compound with ctDNA should be groove binding.

Molecular Docking Studies To further substantiate the biological activity of these compounds, molecular docking studies were performed to characterize the interaction of 1,3,5-triphenyl pyrazole with DNA in Fig. 5. The 3D cocrystal structures of DNA (PDB: 1DNH) is selected as the receptor for molecular docking study. The results from the molecular docking indicated that these compounds bind to the minor groove of DNA sequences. Compounds $\mathbf{5 e}$ and $\mathbf{5 q}$ are complementary to that of the DNA groove, and a similar binding affinity was observed in comparison with the Niacin 33258 (the original ligands of 1DNH). The methoxy groups and the alkylamine groups on both ends of the ligand were involved in extensive and dynamic H-bonds to the DNA bases. Molecular docking and fluorescence studies also support this claim.

Antitopoisomerase Activity The enzymes which control the topology of DNA are called topoisomerases and play a crucial role in several important processes such as DNA replications, transcription, segregation and recombination. ${ }^{25)}$ The two major classes of topoisomerase type I (topo I) and type II (topo II), are mainly classified by cleavage of single-stranded or double-stranded DNA, respectively. ${ }^{26)}$ Generally, in various tumor cells, topoisomerase is expressed much more than in normal cells, so the modulating of topoisomerase levels

\section{B) $5 q$}

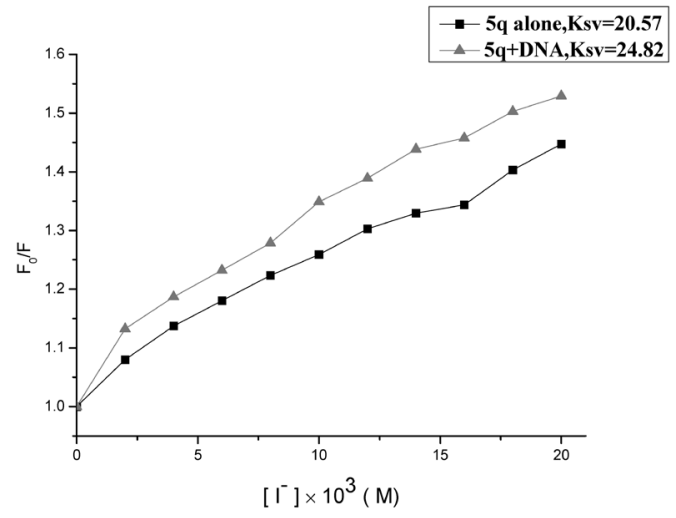

Fig. 4. KI Quenching Studies

Stern-Volmer plot to calculate the KI quenching constant in absence and presence of DNA. Slight increase in $K_{\mathrm{SV}}$ value is obtained in case of groove binding. 
(A) Niacin 33258

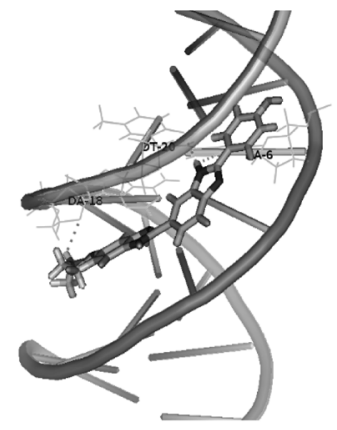

(B) compound 5e

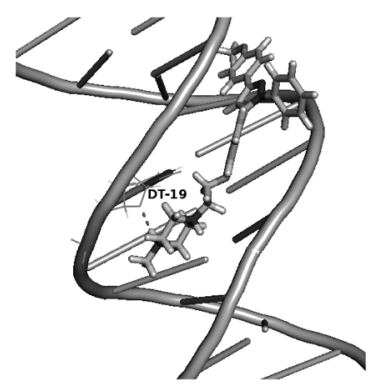

(C) compound $5 q$

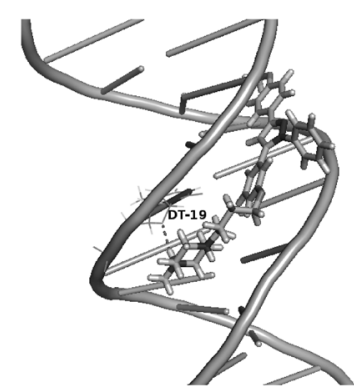

Fig. 5. View of Niacin 33258 (A) Compound 5e (B) and 5q (C) Docked in the DNA Binding Domain

A) $100 \mu \mathrm{M}$

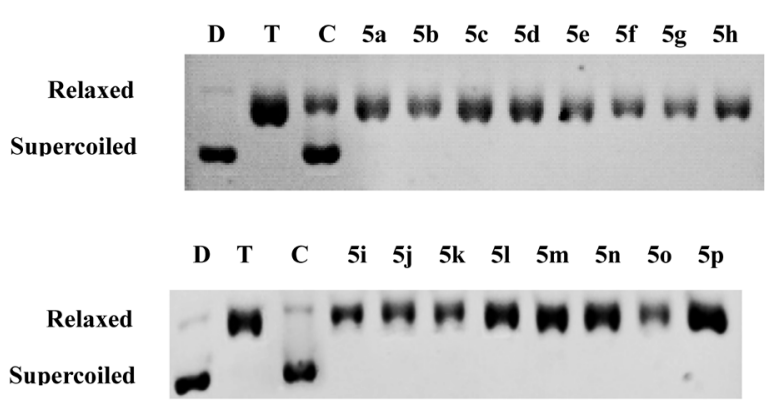

$\begin{array}{lllll}D & \text { T } & \text { C } & 5 q & 5 r\end{array}$

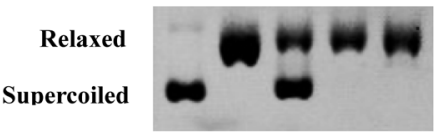

Lane D: pBR322 only,

Lane T: pBR322 + topoisomerase I,

Lane C: pBR322 + topoisomerase I + Camptothecin,

Lane 5a-5r: pBR322 + topoisomerase I + compounds 5a-5r

Fig. 6. Topoisomerase I Inhibitory Activity of Compounds $\mathbf{5 a}-\mathbf{5 r}$

could be an important treatment for cancer. ${ }^{27)}$ Well-known topoisomerases I and II inhibitors, camptothecin and etoposide, were used as positive controls. The reaction products of topoisomerases I and II relaxation assays were analyzed by electrophoretic mobility and developed in ethidium bromide in the presence of UV light. The inhibitory activities were evaluated at $100 \mu \mathrm{M}$ for all compounds. Only those compounds with moderate to significant activity were tested further at $20 \mu \mathrm{M}$.

Antitopoisomerase I Activity All of the compounds showed no inhibitory activity on topo I at $100 \mu \mathrm{M}$ concentrations. Figure 6 showed that the DNA fraction of super helicoidal was completely relaxed by the enzyme topo I.

Antitopoisomerase II Activity As shown in Fig. 7, most of the compounds $(\mathbf{5} \mathbf{c}, \mathbf{5 h}, \mathbf{5 k}, \mathbf{5 l}, \mathbf{5 m}, \mathbf{5 n}, \mathbf{5 q}, \mathbf{5 r})$ showed topoisomerase II inhibitory activity at $100 \mu \mathrm{M}$. Noteworthy, the compounds of $5 \mathbf{r}$ (48.2 and $13.3 \%$ at 100 and $20 \mu \mathrm{M}$, respectively) showed better topoisomerase II inhibitory activity.

It was suggested that the cytotoxic activity of 5e was not due to topo II inhibition and the cytotoxic activity of $\mathbf{5 q}$ showed lower topoisomerase II inhibitory activity. However,
A) $100 \mu \mathrm{M}$
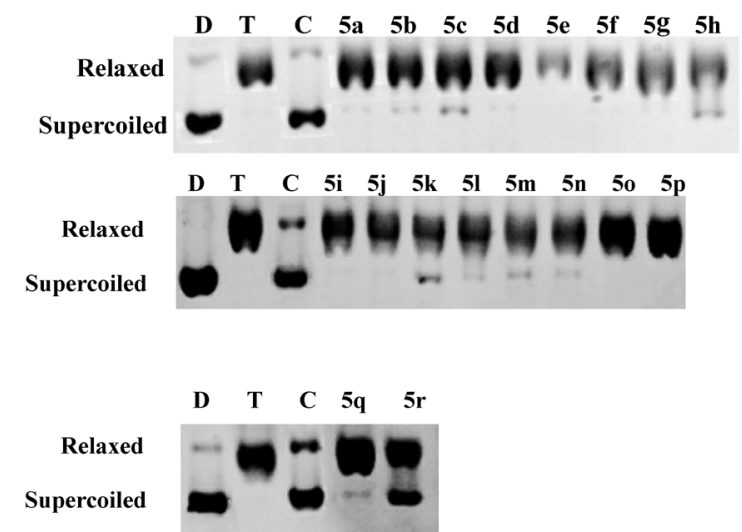

B) $20 \mu \mathrm{M}$

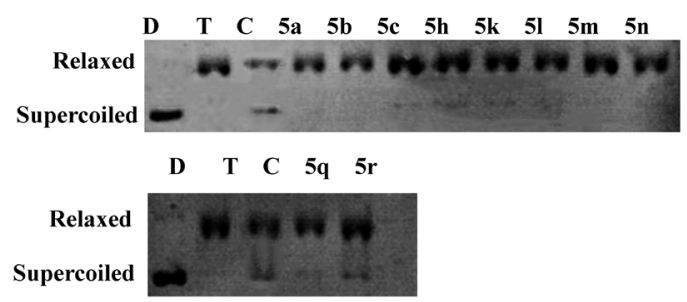

Lane D: pBR322 only,

Lane T: pBR322 + topoisomerase II,

Lane C: pBR322 + topoisomerase II + Etoposide,

Lane 5a-5g: pBR322 + topoisomerase II + compounds 5a-5r

Fig. 7. Topoisomerase II Inhibitory Activity of Compounds $\mathbf{5 a}-\mathbf{5 r}$

according to research findings, pyrazole compounds have a wide range of biological targets. ${ }^{28-30)}$ In future analysis, other target molecules will be investigated for better elucidation of the action mechanism of the new pyrazole derivatives synthesized in this work.

\section{Conclusion}

In conclusion, a novel series of 1,3,5-triphenyl pyrazole compounds were synthesized, and their antiproliferative properties were evaluated against four human cancer cell lines. Especially, the compounds $\mathbf{5 e}$ and $\mathbf{5 q}$ showed higher antitumor activity with $\mathrm{IC}_{50}$ values $<13 \mu \mathrm{M}$ for the tested cell lines. Compounds $\mathbf{5 e}$ and $\mathbf{5 q}$ did not inhibit the topoisomerase activity evaluated by relaxation assay. However, the DNA binding 
studies disclosed that they are DNA minor groove binding and the docking studies correlated with DNA binding studies. The findings give us an insight into the DNA binding mechanism and the anticancer activity of these 1,3,5-triphenyl pyrazole compounds. Overall, these studies are very important to understand the role of 1,3,5-triphenyl pyrazole compounds for the cytotoxic activity and DNA binding ability. And the positive charges can be used as a strategy for increasing the DNA binding affinity and anticancer activity of these compounds. It is suggested that these compounds may act as potential anticancer agents.

Acknowledgments We gratefully acknowledge the funding support from National Natural Science Foundation of China (No. 21675039); China Postdoctoral Science Foundation (No. 2016M591401); Young Talent of Hebei Province; Natural Science Foundation of Hebei Province (No. B2018201269); Hebei University Science Fund for Distinguished Young Scholars (No. 2015JQ06).

Conflict of Interest The authors declare no conflict of interest.

Supplementary Materials The online version of this article contains supplementary materials.

General chemistry methods, synthesis procedures, spectral data, biological assays, molecular docking are given in supplementary materials.

\section{References}

1) Torre L. A., Siegel R. L., Ward E. M., Jemal A., Cancer Epidemiol. Biomarkers Prev., 25, 16-27 (2016).

2) Jain A. K., Bhattacharya S., Bioconjug. Chem., 22, 2355-2368 (2011).

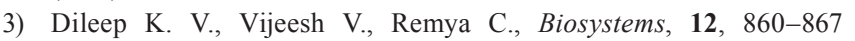
(2016).

4) Wang J. C., Annu. Rev. Biochem., 65, 635-692 (1996).

5) Nitiss J. L., Biochim. Biophys. Acta, 1400, 63-81 (1998).

6) Forterre P., Gribaldo S., Gadelle D., Serre M. C., Biochimie, 89, 427-446 (2007).

7) Demarquay D., Huchet M., Coulomb H., Lesueur-Ginot L. Lavergne O., Kasprzyk P. G., Bailly C., Camara J., Bigg D. C., Anticancer Drugs, 12, 9-19 (2001).
8) Baldwin E. L., Osheroff N., Curr. Med. Chem., 5, 363-372 (2005).

9) Lyu Y. L., Kerrigan J. E., Lin C. P., Azarova A. M., Tsai Y. C., Ban Y., Liu L. F., Cancer Res., 67, 8839-8846 (2007).

10) Murdock K. C., Child R. G., Fabio P. F., Angier R. D., Wallace R. E., Durr F. E., Citarella R. V., J. Med. Chem., 22, 1024-1030 (1979).

11) Chavan H. V., Bandgar B. P., Adsul L. K., Dhakane V. D., Bhale P. S., Thakare V. N., Masand V., Bioorg. Med. Chem. Lett., 23, 1315-1321 (2013)

12) Lowe G., Droz A. S., Vilaivan T., Weaver G. W., Tweedale L., Pratt J. M., Rock P., Yardley V., Croft S. L., J. Med. Chem., 42, 999-1006 (1999).

13) Lansiaux A., Dassonneville L., Facompré M., Kumar A., Stephens C. E., Bajic M., Tanious F., Wilson W. D., Boykin D. W., Bailly C., J. Med. Chem., 45, 1994-2002 (2002).

14) Jahng Y., Zhao L. X., Moon Y. S., Basnet A., Kim E. K., Chang H. W., Ju H. K., Jeong T. C., Lee E. S., Bioorg. Med. Chem. Lett., 14, 2559-2562 (2004).

15) Batovska D., Parushev S., Slavova A., Bankova V., Tsvetkova I., Ninova M., Najdenski H., Eur. J. Med. Chem., 42, 87-92 (2007).

16) Breslow D. S., Hauser C. R., J. Am. Chem. Soc., 62, 2385-2388 (1940).

17) Narender T., Reddy K. P., Tetrahedron Lett., 48, 3177-3180 (2007).

18) Zhou C. Y., Xi X. L., Yang P., Biochemistry, 72, 37-43 (2007).

19) Zhang G., Hu X., Fu P., J. Photochem. Photobiol. B, 108, 53-61 (2012).

20) Shah A., Nosheen E., Munir S., Badshah A., Qureshi R., Zia-urRehman, Muhammad N., Hussain H., J. Photochem. Photobiol. B, 120, 90-97 (2013).

21) Nagle P. S., Mckeever C., Rodriguez F., Nguyen B., Wilson W. D., Rozas I., J. Med. Chem., 57, 7663-7672 (2014).

22) Rehman S. U., Sarwar T., Ishqi H. M., Husain M. A., Hasan Z., Tabish M., Arch. Biochem. Biophys., 566, 7-14 (2015).

23) Sadeghi M., Bayat M., Cheraghi S., Yari K., Heydari R., Dehdashtian S., Shamsipur M., Luminescence, 31, 108-117 (2016).

24) Zhang G., Wang L., Zhou X., Li Y., Gong D., J. Agric. Food Chem. 62, 991-1000 (2014).

25) Nitiss J. L., Beck W. T., Eur. J. Cancer, 32, 958-966 (1996).

26) Sherer C., Snape T. J., Eur. J. Med. Chem., 97, 552-560 (2015).

27) Pommier Y., Nat. Rev. Rheumatol., 6, 789-802 (2006).

28) Evstigneev M. P., Rybakova K. A., Davies D. B., Biophys. Chem., 121, 84-95 (2006)

29) Croney J. C., Jameson D. M., Learmonth R. P., Biochem. Mol. Biol. Educ., 29, 60-65 (2001).

30) Beraldo H., Garniersuillerot A., Tosi L., Lavelle F., Biochemistry, 24, 284-289 (1985). 